\title{
Family history of malignant neoplasm and its relation with clinicopathologic features of gastric cancer patients
}

\author{
Junxiu Yu ${ }^{1^{*}}, \mathrm{Bo} \mathrm{Fu}{ }^{2}$ and Qi Zhao ${ }^{2}$
}

\begin{abstract}
Background: Few studies to date have evaluated gastric cancer(GC)-related malignant neoplasm family history $(\mathrm{MN}-\mathrm{FH})$, and their findings have been largely inconsistent. The aim of this study is to evaluate the prevalence of $\mathrm{MN}-\mathrm{FH}$ and its relation to the clinicopathologic features of GC.

Methods: A total of 104 hospitalized patients with primary gastric adenocarcinoma was prospectively analyzed from 2008 to 2009. Positive MN-FH was defined as MN-affected first- and second-degree relatives of the current GC cases. The relation between prevalence of positive MN-FH and clinicopathologic features in the current GC patients was assessed using the Chi-square test with Cramer's V coefficient.

Results: Thirty-seven (35.6\%) of the GC patients had positive MN-FH, with 42 associated tumors in first- and second-degree relatives. Twenty-six (61.9\%) of the associated tumors were located in the digestive system, including the esophagus (26.2\%), stomach (23.8\%), liver (9.5\%) and colon (2.4\%). Lung cancers were the most prevalent non-digestive system-associated tumors (9.5\%). Correlation analysis revealed no significant relations with prevalence of $\mathrm{MN}-\mathrm{FH}$ and any of the clinicopathologic features (all, $P>0.05)$, including sex $(V=0.044)$, age $(V=0.060)$ and histological subtypes $(V=0.109)$.

Conclusions: More than one-third of the GC patients in our hospital had positive MN-FH. The most frequent forms of MN-FH were esophageal cancer and GC. The prevalence of positive MN-FH was not correlated to any of the clinicopathologic features, including sex, age and histological subtypes in the study population of GC patients.
\end{abstract}

Keywords: Gastric cancer, Family history, Malignant neoplasm, Sex, Age, Histological subtypes

\section{Background}

Gastric cancer (GC) is one of the most common malignant tumors diagnosed worldwide. Although the incidence of GC in many developed countries has shown a downward trend over the past decade, over 980,000 new cases were estimated in 2008 [1], $70 \%$ of which occurred in developing countries. GC is not only the second most common malignant tumor reported in China [1], but accounted for more than 460,000 new cases and more than 350,000 deaths in 2008 alone [2].

The majority of GC cases worldwide are believed to be sporadic. Only about $10 \%$ of GC cases show familial

\footnotetext{
* Correspondence: yujxsd@hotmail.com

'Department of Gastrointestinal Surgery, Liaocheng People's Hospital and Liaocheng Clinical School of Taishan Medical University, 67 West Dongchang Road, Liaocheng, Shandong Province 252000, China

Full list of author information is available at the end of the article
}

aggregation, which is defined as two or more GC patients in close relatives [3]. Furthermore, only 1 to $3 \%$ of GC cases have been diagnosed as hereditary syndromes [4]. Familial gastric cancer (FGC) has been associated with environmental factors, such as Helicobacter pylori infection and a high salt diet, and genetic factors, such as E-cadherin mutations [5,6]; however, it is possible that interactions between environmental and genetic factors may increase the risk of FGC or promote its pathogenic progress.

Familial history of malignant neoplasm (MN-FH) has been characterized as a risk factor of GC, due to the fact that close family members are often exposed to similar environmental risk factors and are subject to inherited genetic susceptibility [7]. However, the exact environmental and genetic factors differ for families in different areas [8], creating a regional disparity for MN-FH risk. Therefore,

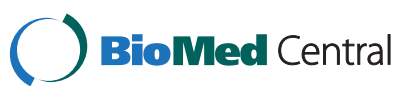


determining the prevalence of $\mathrm{MN}-\mathrm{FH}$ in particular regions and evaluating its relation with the clinicopathologic features of GC patients may help in designing effective diagnostic and therapeutic strategies to reduce the number of cases of GC in high-risk areas, such as in China. Few studies [9-12] to date have evaluated GC-related MN$\mathrm{FH}$, and their findings have been largely inconsistent. We conducted a study of GC patients in the Shandong Province of in the north of China to determine if $\mathrm{MN}$ $\mathrm{FH}$ was a risk factor for $\mathrm{GC}$ and whether it was related to any clinicopathologic features of current GC patients.

\section{Methods}

A total of 104 patients diagnosed with primary gastric adenocarcinoma and hospitalized in the Department of Gastrointestinal Surgery at Liaocheng People's Hospital (Shandong, China) from January 2008 to December 2009, was enrolled in our prospective study. The MN-FH for each case was determined upon admission by a single investigator (JXY), who relied on patient self-reporting or reporting by an accompanying spouse or adult-age child. Positive $\mathrm{MN}-\mathrm{FH}$ was defined as malignant neoplasm-affected firstand second-degree relatives of the current GC case.

The study did not include any intervention beyond the prescribed treatment regimens and histological types, (defined by World Health Organization (WHO) standards [13]), which were obtained from the patient records. The study was approved by the Ethical Committee of Liaocheng People's Hospital.

All statistical analyses were carried out with SAS software v9.0 (SAS Institute, Cary, NC, USA). The Chi-square $\left(\chi^{2}\right)$ test was used to evaluate the correlation between MN-FH prevalence and various clinicopathological features using the Cramer's V coefficient. Statistical significance was indicated by a $P$-value less than 0.05 .

\section{Results}

Of the 104 GC cases in this study, 76 were male and 28 were female. The median age was 58 years old (range: 22 to 80 years). Thirty-seven (35.6\%) of the GC cases had positive MN-FH, with 42 associated tumors in first- and second-degree relatives.

The 42 associated malignant tumors and their frequencies are listed in Table 1. Twenty-six (61.9\%) of the associated tumors were located in the digestive system (esophagus, stomach, liver and colon). Twenty-two (52.4\%) of the associated tumors were located in the alimentary tract (esophagus, stomach and colon). The ratios of esophageal cancer and gastric cancer MN-FH were 26.2\% and $23.8 \%$, respectively. Those cancers very rarely represented by the associated tumors (each 1/42) included colon, breast, brain, nasopharangeal and ocular.

As shown in Table 2, there were no significant differences in the MN-FH prevalence among different sexes
Table 1 The location of associated tumors in gastric cancer patients with positive malignant neoplasm family history

\begin{tabular}{lll}
\hline Associated malignant neoplasm & Number & Constituent ratio, \% \\
\hline Esophageal carcinoma & 11 & 26.2 \\
Gastric cancer & 10 & 23.8 \\
Liver cancer & 4 & 9.5 \\
Lung cancer & 4 & 9.5 \\
Cervical/endometrial cancer & 2 & 4.8 \\
Colon cancer & 1 & 2.4 \\
Breast cancer & 1 & 2.4 \\
Brain glioma & 1 & 2.4 \\
Nasopharyngeal carcinoma & 1 & 2.4 \\
Eye malignant neoplasm & 1 & 2.4 \\
Uncertain malignant neoplasm & 6 & 14.3 \\
Total & 42 & 100 \\
\hline
\end{tabular}

$(\mathrm{V}=0.044)$, ages $(\mathrm{V}=0.060)$, or histological subtypes $(\mathrm{V}=$ 0.109 ) of the current GC patients (all, $P>0.05$ ).

\section{Discussion}

Family history of malignant neoplasm as a risk factor for GC An earlier large-scale retrospective study [14] had reported that family history is a sufficiently reliable predictor of cancer risk for all types of cancers. While our study was smaller in scale $(\mathrm{n}=104)$ and more focused (all Chinese from a single region), it was prospective in nature and, unlike the earlier study, not solely based on a questionnaire administered by multiple investigators. The author (JXY) as a single investigator collected data in-person with the aim of increasing our study's reliability.

Our results showed $35.6 \%$ of 104 patients with GC presented with $\mathrm{MN}-\mathrm{FH}$ in first- and second-degree relatives. This percentage is notably lower than that reported from a study in Japan (46.4\%) [11]; however, the higher GC incidence in Japan may account for the overall higher $\mathrm{MN}-\mathrm{FH}$ prevalence. Another study of Italian GC patients reported $\mathrm{MN}-\mathrm{FH}$ for $70.8 \%$ of the study population [10]. It is possible that this remarkably high MN-FH may reflect an ethnicity-related genetic susceptibility. Ten (9.61\%) of the 104 GC patients in our study had one or more first- and second-degree relatives with GC. This familial clustering of GC agrees with previous reports stating that approximately $90 \%$ of GC cases are sporadic and only approximately $10 \%$ present familial clustering $[3,4]$.

Most MN-FH associated tumors of GC patients were located in the digestive system, especially in the esophagus and stomach

Our results showed that more than one-half $(61.9 \%)$ of associated tumors in $\mathrm{MN}-\mathrm{FH}$ were located in the digestive system. Likewise, a previous study of $\mathrm{MN}-\mathrm{FH}$ in second- 


\begin{tabular}{|c|c|c|c|c|c|}
\hline $\begin{array}{l}\text { Clinicopathologic } \\
\text { parameter }\end{array}$ & $\begin{array}{l}\text { Number } \\
\text { of total } \\
\text { patients }\end{array}$ & $\begin{array}{l}\text { Number } \\
\text { of patients } \\
\text { with positive } \\
\text { MN-FH, } n(\%)\end{array}$ & Cramer's V & $x^{2}$ & $\begin{array}{l}P \text { - } \\
\text { value }\end{array}$ \\
\hline Sex & & & 0.044 & 0.197 & 0.657 \\
\hline Male & 76 & $28(36.8)$ & & & \\
\hline Female & 28 & $9(32.1)$ & & & \\
\hline Ages, years & & & 0.060 & 0.368 & 0.832 \\
\hline$<45$ & 22 & $9(40.9)$ & & & \\
\hline 45 to 60 & 39 & $13(33.3)$ & & & \\
\hline$>60$ & 43 & 15 (34.9) & & & \\
\hline \multicolumn{6}{|l|}{ Histology } \\
\hline$T_{U} B^{a}$ & 19 & $5(26.3)$ & 0.109 & & $0.776^{*}$ \\
\hline $\mathrm{POR}^{\mathrm{b}}$ & 69 & 27 (39.1) & & & \\
\hline$S I G^{c}$ & 10 & $3(30.0)$ & & & \\
\hline$M U C^{d}$ & 6 & $2(33.3)$ & & & \\
\hline
\end{tabular}

*: Fisher's exact test.

${ }^{a}$ TUB, tubular adenocarcinoma; ${ }^{b} \mathrm{POR}$, poorly differentiated adenocarcinoma;

${ }^{\mathrm{c}} \mathrm{SIG}$, signet-ring cell carcinoma; ${ }^{\mathrm{d}} \mathrm{MUC}$, mucinous adenocarcinoma.

degree relatives of Chinese GC patients from the Guandong Province in the south of China determined that $74.9 \%$ of associated tumors were located in the stomach, esophagus, liver and colorectum. A study of MN-FH in Japanese GC patients also found that $70.9 \%$ of total associated malignant neoplasms involved organs of the digestive system (stomach, colorectum, liver, esophagus and pancreas) [11]. However, the reported prevalence of each organ-specific MN-FH-associated tumor was different for different regions. Our study population from north of China had the highest amount of associated tumors in the esophagus (26.2\%), followed by the stomach (23.8\%). The report cited above, using GC patients from south of China, found notably different percentages of stomach- and esophagus-associated tumors $(38.6 \%$ and $18.3 \%$, respectively) [15]. In contrast, the study of Japanese GC patients found that $40.9 \%$ of associated tumors were located in the stomach [11], while the study of Italian GC patients found that only $21.9 \%$ of associated tumors were located in the stomach [10]. The exact reasons for this regional disparity should be analyzed in future studies that consider ethnic-related factors, such as heredity, and environmental exposures, such as geographic or cultural factors.

The risk of GC was higher in individuals with a positive MN-FH of digestive cancers. A case-control study from the USA found that the risk for GC patients was increased by an MN-FH of digestive cancers, even after adjusting for other risk factors, such as age, race, smoking and body mass index (BMI) [16]. Another case-control study of GC patients in Taiwan identified positive family history of GC as a significant risk factor for GC [17]. Again, the MN-FH risk determined by each of the studies using different patient populations showed regional differences. A review of the related literature indicated that the risk ratio was higher in Asians than in Europeans [18]. Specifically, the relative risk for $\mathrm{GC}$ in individuals with a positive family history of GC varied from 1.5-fold to 3.5-fold, compared with individuals with a negative family history of GC [18]. Thus, it is not surprising that our study group had unique profiles of organ-specific associated tumors from MN-FH.

\section{Colorectal and breast cancers are not common associated tumors in GC patients}

Colorectal cancer has been identified as a common associated tumor in MN-FH by previous studies of non-Chinese GC patient populations. It ranked second among the associated tumors reported by both the Italian study (11.1\%) [10] and the Japanese study (16\%) [11]. In our study population, however, only one of the $42 \mathrm{MN}-\mathrm{FH}$ associated tumors was colorectal cancer.

Breast cancer also ranked high (third place; 10.2\%) among the associated tumors in the Italian study [10]. In contrast, breast cancer ranked low (sixth place) in the Japanese study, which found that only $4.3 \%$ of associated tumors were breast cancers [11]. Our result was consistent with the Japanese study, suggesting that some Asian-specific factors may contribute to the MN-FH risk of $\mathrm{GC}$.

It is also possible that these results may simply reflect the different incidences of colorectal cancer and breast cancer in different regions [18]. It is well recognized that incidences of colorectal cancer and breast cancer are higher in Europe than in Japan or China. In addition, European countries have a higher rate of hereditary diffuse gastric cancer (HDGC) than Asian countries. HDGC family history has been associated with breast cancer $[19,20]$, the etiology of which may involve germline mutations in the cadherin-1 (CDH1) gene.

\section{Prevalence of MN-FH does not correlate to GC patient sex, age or histological subtype in Chinese patients} Similar to the Italian study [10], our results showed that there was no correlation between prevalence of MN-FH and sex of GC patients. Specifically, Bernini et al. reported that there were no significant differences in sex among patients with and without a family history of GC [10]. The study of GC patients by Lee et al. [21] also found no differences among males and females in relation to positive family history of cancer.

As for the putative relation with age, the Italian study found no significant correlations between the GC patients with and without a family history of GC (mean ages of 
65.2 and 67.6, respectively) [10], which was similar to our findings. The Japanese study also found no correlation with age (mean ages of patients with family history of GC, with a family history of other cancers, and without a family history of cancer were 64.4, 64.5 and 67.7 years, respectively) [11]. Finally, a comparative analysis of familial and non-familial cancers in USA-based patients found no significant difference in diagnostic age with adenocarcinomas of the esophagus and the gastroesophageal junction [22].

As for the putative relation between GC histological subtypes and MN-FH, both our study and the Japanese study [11] found no significant differences among GC patients. However, an earlier Japanese study [23] did report an increased risk of intestinal type GC when both parents had GC (odds ratio $=7.8$ ), and an increased risk of diffuse-type cancer when both parents had non-GC (odds ratio $=2.1$ ). Intriguingly, the Italian study found that the gastric adenocarcinoma type, as determined by the Lauren classification system, was correlated to family histories of GC [10]. Specifically, the patients with positive family histories of $\mathrm{GC}$ were found to present with more intestinal type GC than those with negative family histories of GC ( $71.8 \%$ vs. $55.1 \%$, respectively).

\section{Conclusions}

More than one-third of the patients had at least one first- or second-degree relative with a cancer diagnosis. The majority of the associated tumors involved digestive system organs, with the esophagus and stomach being the most frequently represented, suggesting that a family history of digestive system cancers may be a risk factor for some GC patients. Colorectal and breast cancers, which have been previously associated with an MN-FH of GC in different ethnicities, were rare MN-FH types in our study population. The MN-FH prevalence was not correlated with patient sex, age or histological subtype.

\section{Abbreviations}

CDH1: Cadherin-1 gene; BMI: Body mass index; FGC: Familial gastric cancer; GC: Gastric cancer; HDGC: Hereditary diffuse gastric cancer; MN-FH: Malignant neoplasm family history; WHO: World Health Organization.

\section{Competing interests}

The authors declare that they have no competing interests.

\section{Authors' contributions}

JXY conceived this study, collected data, performed analysis and drafted the manuscript. BF participated in study design and drafted the manuscript. QZ collected data and performed data analysis. All authors read and approved the final manuscript.

\section{Author details}

${ }^{1}$ Department of Gastrointestinal Surgery, Liaocheng People's Hospital and Liaocheng Clinical School of Taishan Medical University, 67 West Dongchang Road, Liaocheng, Shandong Province 252000, China. ${ }^{2}$ Department of Gastroenterology, Liaocheng People's Hospital and Liaocheng Clinical School of Taishan Medical University, 67 West Dongchang Road, Liaocheng, Shandong Province 252000, China.
Received: 21 October 2012 Accepted: 7 August 2013

Published: 16 August 2013

\section{References}

1. Jemal A, Bray F, Center MM, Ferlay J, Ward E, Forman D: Global cancer statistics. CA Cancer J Clin 2011, 61:69-90.

2. Lin Y, Ueda J, Kikuchi S, Totsuka Y, Wei WQ, Qiao YL, Inoue M: Comparative epidemiology of gastric cancer between Japan and China. World J Gastroenterol 2011, 17:4421-4428.

3. Oliveira C, Seruca R, Carneiro F: Genetics, pathology, and clinics of familial gastric cancer. Int J Surg Pathol 2006, 14:21-33.

4. Corso G, Marrelli D, Roviello F: Familial gastric cancer: update for practice management. Fam Cancer 2011, 10:391-396.

5. Shin CM, Kim N, Yang HJ, Cho SI, Lee HS, Kim JS, Jung HC, Song IS: Stomach cancer risk in gastric cancer relatives: interaction between Helicobacter pylori infection and family history of gastric cancer for the risk of stomach cancer. J Clin Gastroenterol 2010, 44:e34-e39.

6. Fitzgerald RC, Hardwick R, Huntsman D, Carneiro F, Guilford P, Blair V, Chung DC, Norton J, Ragunath K, Van KJH, Dwerryhouse S, Caldas C, International Gastric Cancer Linkage Consortium: Hereditary diffuse gastric cancer: updated consensus guidelines for clinical management and directions for future research. J Med Genet 2010, 47:436-444. Erratum in: J Med Genet 2011,48:216. Van Krieken, Nicola [corrected to Van Grieken, Nicola C.

7. Foschi R, Lucenteforte E, Bosetti C, Bertuccio P, Tavani A, La Vecchia C, Negri E: Family history of cancer and stomach cancer risk. Int J Cancer 2008, 123:1429-1432.

8. Hatakeyama M: Oncogenic mechanisms of the Helicobacter pylori CagA protein. Nat Rev Cancer 2004, 4:688-694.

9. Biedermann K, Vogelsang H, Becker I, Plaschke S, Siewert JR, Hofler H, Keller G: Desmoglein 2 is expressed abnormally rather than mutated in familial and sporadic gastric cancer. J Pathol 2005, 207:199-206.

10. Bernini M, Barbi S, Roviello F, Scarpa A, Moore P, Pedrazzani C, Beghelli S, Marrelli D, de Manzoni G: Family history of gastric cancer: a correlation between epidemiologic findings and clinical data. Gastric Cancer 2006, 9:9-13.

11. Kawasaki K, Kanemitsu K, Yasuda T, Kamigaki T, Kuroda D, Kuroda Y: Family history of cancer in Japanese gastric cancer patients. Gastric Cancer 2007, 10:173-175

12. Wang B, Li Z, Liu C, Xu H, Jin F, Lu P: Family history of cancer in Chinese gastric cancer patients. Chinese-German J ClinOncol 2010, 9:321-326.

13. The International Agency for Research on Cancer: In Pathology and Genetics of Tumors of the Digestive System. Edited by Hamilton SR, Aaltonen LA. New York, NY: WHO Publications; 2000.

14. Bravi F, Bosetti C, Negri E, Lagiou P, La Vecchia C: Family history of cancer provided by hospital controls was satisfactorily reliable. J Clin Epidemiol 2007, 60:171-175.

15. Zhou XF, He YL, Song W, Peng JJ, Zhang CH, Li W, Wu H: Comparison of patients by family history with gastric and non-gastric cancer. World J Gastroenterol 2009, 15:2644-2650.

16. Dhillon PK, Farrow DC, Vaughan TL, Chow WH, Risch HA, Gammon MD, Mayne ST, Stanford JL, Schoenberg JB, Ahsan H, Dubrow R, West AB, Rotterdam H, Blot WJ, Fraumeni JF Jr: Family history of cancer and risk of esophageal and gastric cancers in the United States. Int J Cancer 2001, 93:148-152.

17. Chen MJ, Wu DC, Ko YC, Chiou YY: Personal history and family history as a predictor of gastric cardiac adenocarcinoma risk: a case-control study in Taiwan. Am J Gastroenterol 2004, 99:1250-1257.

18. Yaghoobi M, Bijarchi R, Narod SA: Family history and the risk of gastric cancer. Br J Cancer 2010, 102:237-242.

19. Schrader KA, Masciari S, Boyd N, Wiyrick S, Kaurah P, Senz J, Burke W, Lynch HT, Garber JE, Huntsman DG: Hereditary diffuse gastric cancer: association with lobular breast cancer. Fam Cancer 2008, 7:73-82.

20. Masciari S, Larsson N, Senz J, Boyd N, Kaurah P, Kandel MJ, Harris LN, Pinheiro HC, Troussard A, Miron P, Tung N, Oliveira C, Collins L, Schnitt S, Garber JE, Huntsman D: Germline E-cadherin mutations in familial lobular breast cancer. J Med Genet 2007, 44:726-731.

21. Lee WJ, Hong RL, Lai IR, Chen CN, Lee PH, Huang MT: Clinicopathologic characteristics and prognoses of gastric cancer in patients with a positive familial history of cancer. J Clin Gastroenterol 2003, 36:30-33. 
22. Chak A, Falk G, Grady WM, Kinnard M, Elston R, Mittal S, King JF, Willis JE, Kondru A, Brock W, Barnholtz-Sloan J: Assessment of familiality, obesity, and other risk factors for early age of cancer diagnosis in adenocarcinomas of the esophagus and gastroesophageal junction. Am J Gastroenterol 2009, 104:1913-1921.

23. Eto K, Ohyama S, Yamaguchi T, Wada T, Suzuki Y, Mitsumori N, Kashiwagi $H$, Anazawa S, Yanaga K, Urashima M: Familial clustering in subgroups of gastric cancer stratified by histology, age group and location. Eur J Surg Oncol 2006, 32:743-748.

doi:10.1186/1477-7819-11-201

Cite this article as: Yu et al.: Family history of malignant neoplasm and its relation with clinicopathologic features of gastric cancer patients. World Journal of Surgical Oncology 2013 11:201.

\section{Submit your next manuscript to BioMed Central and take full advantage of:}

- Convenient online submission

- Thorough peer review

- No space constraints or color figure charges

- Immediate publication on acceptance

- Inclusion in PubMed, CAS, Scopus and Google Scholar

- Research which is freely available for redistribution 